\title{
Characterization of the Murine Cytomegalovirus Genes Encoding the Major DNA Binding Protein and the ICP18.5 Homolog
}

\author{
MARTIN MESSERLE, ${ }^{*}$ GÜNTHER M. KEIL,† KARIN SCHNEIDER, ${ }^{\star}$ AND ULRICH H. KOSZINOWSKI*.1 \\ *Department of Virology, Institute for Microbiology, University of UIm, 7900 UIm, Germany; \\ and + Federal Research Centre for Virus Diseases of Animals, 7400 Tubingen, Germany
}

Received May 27, 1992; accepted July 13, 1992

\begin{abstract}
In several herpesviruses the genes for the major DNA binding protein (MDBP), a putative assembly protein, the glycoprotein B (gB), and the viral DNA polymerase (pol) collocate. In murine cytomegalovirus (MCMV), two members of this gene block, pol (Elliott, Clark, Jaquish, and Spector, 1991, Virology 185, 169-186) and gB (Rapp, Messerle, Buhler, Tannheimer, Keil, and Koszinowski, 1992, J. Virol., 66, 4399-4406) have been characterized. Here the two other MCMV genes are characterized, the gene encoding the MDBP and the ICP18.5 homolog encoding a putative assembly protein. Like in human cytomegalovirus (HCMV) the genes order is pol, gB, ICP18.5, and MDBP. The 4.2-kb MDBP mRNA is expressed first in the early phase, whereas the 3.0-kb ICP18.5 mRNA is a late transcript. The open reading frame of the MDBP gene has the capacity of encoding a protein of 1191 amino acids with a predicted molecular mass of $131.7 \mathrm{kDa}$. The MCMV ICP18.5 ORF is translated into a polypeptide of 798 amino acids with a calculated molecular mass of $89.1 \mathrm{kDa}$. Comparison of the amino acid sequences of the predicted proteins of MCMV with the respective proteins of HCMV, Epstein-Barr virus (EBV), and herpes simplex virus type-1 (HSV-1) reveals a striking homology ranging from $72 \%$ (HCMV), 50\% (EBV), to $45 \%$ (HSV-1) for the MDBP sequence and from $74 \%$ (HCMV), 51\% (EBV), to $49 \%$ (HSV-1) for the ICP18.5 sequence. These results establish the close relationship of the two cytomegaloviruses, and underline the usefulness of the murine model for studies on the biology of the CMV infection. (c) 1992 Academic Press, Inc.
\end{abstract}

\section{INTRODUCTION}

Cytomegaloviruses (CMV) are highly species-specific herpesviruses that infect many animals. Human cytomegalovirus (HCMV) is an ubiquitous human pathogen. Although primary infection in the immunocompetent host is often not accompanied by an apparent disease, a state of livelong persistence is established (Ho, 1982). Severe immunosuppression or immunodeficiency can cause reactivation of the HCMV infection from the latent state. Therefore, HCMV is a major threat for organ allograft recipients and HIV patients (Pass, 1991). Apparently, host defense mechanisms rather than viral properties define the different manifestations of CMV disease. Therefore, the development of an efficacious vaccine or treatment against HCMV needs a thorough analysis of the viral pathogenesis and of the immune response against CMV antigens. Due to the species specificity of HCMV the experimental analysis of virus-host interactions is limited. Thus, the availability of animal models are important in defining the key elements of CMV control.

A series of similarities have been reported between murine (MCMV) and human CMV (Ho, 1982). Both

\footnotetext{
The nucleotide sequence data reported in this paper have been submitted to the GenBank nucleotide sequence database and have been assigned Accession Number X67021.

' To whom reprint requests should be addressed.
}

MCMV and HCMV lead to the infection of the spleen, salivary and adrenal glands, and lungs of their respective hosts. Pneumonia is the major cause of mortality following MCMV or HCMV infection. Therefore, the infection of mice with MCMV has been used as a model system to study various parameters of CMV infections including the reactivation following immunosuppres. sive treatment (Jordan et al., 1977) and the cellular immune response against $\mathrm{CMV}$ antigens (Koszinowski et al., 1990).

Despite of the obvious similarities of the two viruses in biology and pathogenesis, it is not known whether the similarity is also reflected at the molecular level. However, a molecular approach to virus control will only be feasible when the factors contributing to viral pathogenesis and antiviral immunity are defined at the genetic level. Whereas the complete sequence of the HCMV genome has been determined (Chee et al., 1990), only a few MCMV genes and proteins have been analyzed so far (Keil et al., 1987; Bühler et al., 1990; Elliott et al., 1991; Loh et al., 1991; Messerle et al., 1992; Rapp et al., 1992). In order to study the homology of the two CMV genomes we have determined the nucleic acid sequence of a region of the MCMV genome, which contains a series of genes conserved throughout all herpesviruses.

Here we report the nucleic acid sequence and the transcriptional patterns of two MCMV genes encoding 
proteins with a high degree of amino acid sequence homology to the major DNA binding protein and a putative assembly protein of HCMV and herpes simplex virus (HSV).

\section{MATERIALS AND METHODS}

\section{Virus and cell culture}

MCMV (mouse salivary gland virus strain Smith, ATCC VR-194) was propagated on BALB/c mouse embryonal fibroblasts (MEF) as described previously (Keil et al., 1984).

\section{Cloning procedures and sequence analysis}

$B a m \mathrm{HI}$ subclones of the MCMV HindlII D fragment were generated and these were further subcloned as EcoRI or Pstl fragments. The nucleic acid sequence was determined by a modified version of the dideoxy sequencing method (Tabor and Richardson, 1987), using nuclease $B a / 31$-generated subclones of the EcoRI and $P$ stl fragments. When necessary deaza-dGTP was used in the sequencing reactions instead of dGTP to avoid compressions. Sequences were either determined for both strands or several overlapping subclones were used to confirm the sequence. Appropriate primers were synthesized and used to define the overlapping sequences between the EcoRI and Pstl subclones, respectively. Overlaps between the BamHI fragments were determined by sequence analysis of polymerase chain reaction amplified fragments. The Genetics Computer Group software package version 7.0 from April 1991 (Devereux et al., 1984) was used for the analysis of the nucleic acid sequences and for the deduction of the amino acid sequences. Comparison of the nucleotide sequences of the identified open reading frames and of the deduced amino acid sequences was performed to the entries of the Genbank database release 69 from September 1991.

\section{Isolation of RNA}

MEF were MCMV infected with 20 PFU per cell by using the technique of centrifugal enhancement of infectivity at $800 \mathrm{~g}$ for $30 \mathrm{~min}$. At different time points postinfection whole-cell RNA was prepared from MCMV-infected cells following established procedures (Chirgwin et al., 1979).

\section{Northern (RNA) blot hybridization and nuclease S1 protection experiments}

RNA samples were size fractionated by gel electrophoresis and transferred to nitrocellulose filters as described previously (Keil et al., 1984). DNA probes used for hybridization were labeled with $\left[\alpha^{-}{ }^{32} P\right] d C T P$ by us- ing a multiprime DNA labeling system (BoehringerMannheim, Germany). For estimation of RNA sizes, Escherichia coli $16 \mathrm{~S}$ and $23 \mathrm{~S}$ rRNAs and $18 \mathrm{~S}$ and 28 $S$ mouse rRNAs were used as size markers. Whole-cell RNA was hybridized to $5^{\prime}$ or $3^{\prime}$ end-labeled DNA fragments and digested with nuclease $\mathrm{S} 1$ as described previously (Keil et al., 1987). Nuclease-resistant fragments were size fractionated on denaturing sequencing gels.

\section{$3^{\prime}$ end determination}

The $3^{\prime}$ end of the MCMV ICP18.5 mRNA was determined according to the protocol of Frohman et al. (1988) using the oligonucleotides (dT)17-R1-R0 (5'AAGGATCCGTCGACATCGATAATACGACTCACTATAGGGATTTTTTTTTTTTTTTTTT-3'), RO (5'-AAGGATCCGTCGACATC-3'), and End 1 (5'-GCAAGCTTATGTCAGGTCGAGAG-3'). The primer End 1 corresponds to positions 6278 to 6295 in Fig. 2, immediately upstream of the Smal site at map unit 0.375 (Fig. 4).

\section{RESULTS}

\section{Nucleotide sequence of the MCMV MDBP and ICP18.5 genes}

A conserved gene block containing the genes for the major DNA-binding protein (MDBP), a putative assembly protein, the glycoprotein $\mathrm{B}(\mathrm{gB})$, and the viral DNA polymerase (pol) has been described for all herpesviruses (Kouzarides et al., 1987). We assumed that the analysis of this gene block could help to define the degree of relatedness between murine and human CMV. The pol and gB genes of MCMV have been sequenced (Elliott et al., 1991; Keil, unpublished data; Rapp et al., 1992), and the location of gB has been mapped to the left end of the MCMV Hind III D fragment and pol overlaps the border between the Hindlil $D$ and $\mathrm{H}$ fragments (Fig. 1). Assuming the same gene order as in HCMV, we expected that the MCMV genes encoding the MDBP and the putative assembly protein, which we call MCMV ICP18.5 gene in analogy to the gene in the HSV-1 genome (Pellett et al., 1986), to be located upstream of the glycoprotein $B$ gene. Consequently, we analyzed the nucleic acid sequence upstream of the glycoprotein B gene (Fig. 1).

The nucleotide sequence from the Xhol site at map unit 0.401 up to the EcoRI site at map unit 0.371 is shown in Fig. 2. Two large open reading frames (ORF) of 3573 and 2394 nucleotides (nt) extending from positions 256 to 3828 and from positions 4038 to 6431 were identified. A third ORF starting at position 6334 encodes the MCMV glycoprotein B (Rapp et al., 1992). 


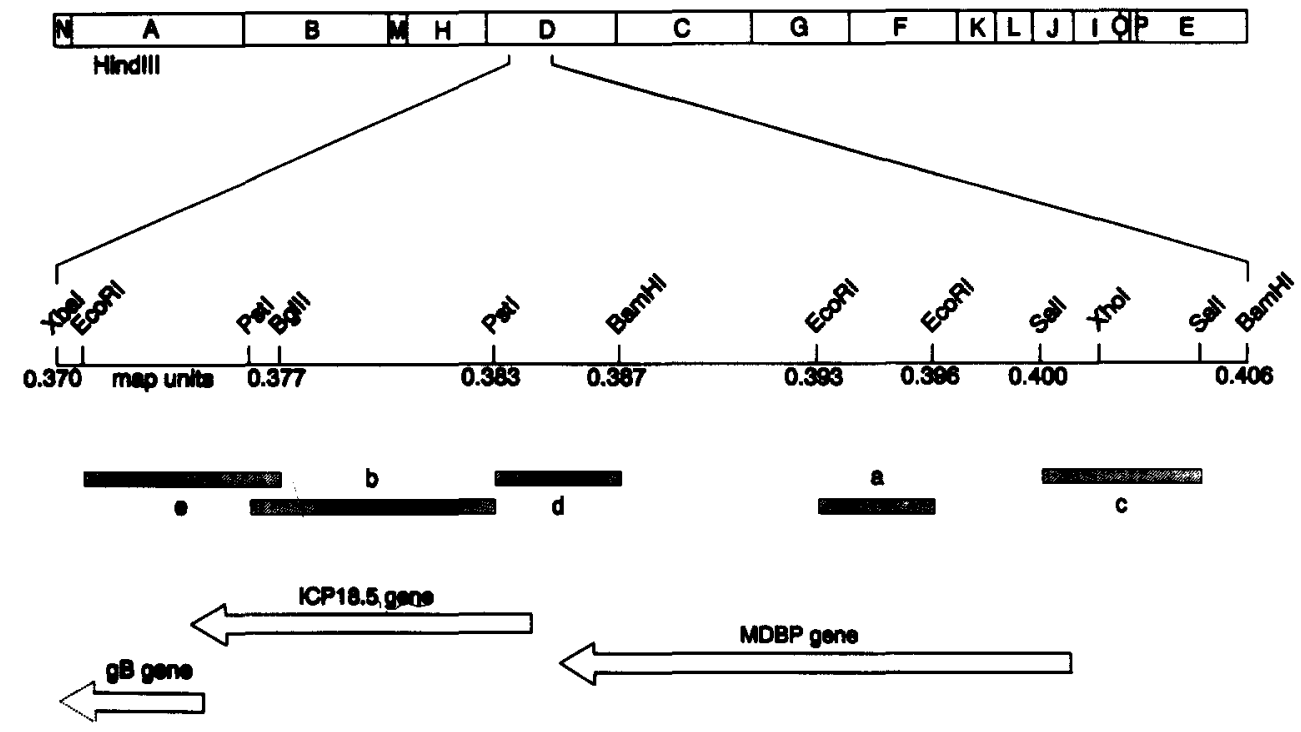

FIG. 1. Localization of the MCMV genes encoding the ICP18.5 homolog and the major DNA binding protein (MDBP). (Top) Hindlll cleavage map of the MCMV strain Smith genome. (Middle, enlarged) Positions (in map units) of restriction enzyme sites in the analyzed part of the HindlII D fragment. The hatched bars represent DNA probes used in the Northern blot analysis. (Bottom) Localization of the identified open reading frames (open bars).

The ORF of the MCMV ICP18.5 gene overlaps the ORF of the glycoprotein $\mathrm{B}$ gene by 32 codons. The nucleotide sequences of the MCMV ICP18.5 and MDBP ORFs showed 65 and $60 \%$ homology to the UL56 and UL57 ORFs of the HCMV genome (Chee et al., 1990). Remarkably, the sequences upstream of the MDBP ORF (map units 0.401 to 0.406 ) and the $200 \mathrm{nt}$ between the MDBP and ICP18.5 ORFs display almost no similarity to the corresponding sequences in the HCMV genome.

\section{Expression kinetics of the MCMV MDBP and ICP18.5 genes}

Northern (RNA) blot hybridizations were performed to determine the expression kinetics of the MDBP and ICP18.5 genes. Hybridization with a 821-bp EcoRI fragment (Fig. 1, probe a; map units 0.396 to 0.393 ) from the MDBP ORF resulted in a band of $4.2 \mathrm{~kb}$ (Fig. 3a). The MDBP mRNA appeared as early as $2 \mathrm{hr}$ p.i. and remained present throughout the replication cycle (Fig. 3a, lanes 3 to 6).

The size of the ICP18.5 mRNA and the expression kinetics of the ICP18.5 gene was determined by using a 1734-bp Pstl fragment from the ICP18.5 ORF (Fig. 1, probe b; map units 0.383 to 0.376 ) as ${ }^{32}$ P-labeled probe. A transcript of $3.0 \mathrm{~kb}$ was seen $24 \mathrm{hr}$ p.i. (Fig. $3 b)$. Thus, the MCMV ICP18.5 gene represents a late gene.

To define the approximate ends of the MDBP and ICP18.5 transcripts Northern blot hybridizations were performed using DNA probes which overlap the ends of the putative open reading frames (see Fig. 1, probes c to e). A 1034-bp Sall fragment (Fig. 1, probe c; map units 0.4045 to 0.400 ) showed a weak hybridization with the 4.2-kb MDBP mRNA (Fig. 3c). This result suggested that the $5^{\prime}$ end of the MDBP mRNA is located within this Sall fragment. Hybridization with a 856-bp BamHI/Pstl fragment (Fig. 1, probe d; map units 0.387 to 0.383 ) revealed the MDBP transcript as well as the late ICP18.5 transcript (Fig. 3d, lanes 3 and 4). Therefore, the $3^{\prime}$ end of the MDBP mRNA and the $5^{\prime}$ end of the ICP18.5 transcript are located within the BamHI/ Pstl fragment. The 1389-bp Bg/ll/EcoRl fragment (Fig. 1 , probe e; map units 0.377 to 0.371 ) showed hybridization to the $3.0-\mathrm{kb}$ ICP18.5 transcript, to a $3.3-\mathrm{kb}$ transcript, and to additional bands of higher molecular mass. The 3.3-kb band represents the glycoprotein $B$ mRNA and the larger transcripts also represent gB-

FIG. 2. Nucleotide sequence of the MCMV MDBP and ICP18.5 genes and deduced amino acid sequence of the encoded proteins. The nucleotide sequence is shown from the Xhol site at map unit 0.401 up to the EcoRI site at map unit 0.371 . Open reading frames are indicated by capital letters and the deduced amino acid sequence is shown below in the one-letter code. $5^{\prime}$ cap sites and $3^{\prime}$ ends of the mRNAs are marked by stars and dots, respectively. Putative binding sites for the transcription factor SP1 are underlined, and potential TATA-boxes are underlined and marked by capital letters. Some restriction enzyme sites are shown for orientation. 
xhel

Spl

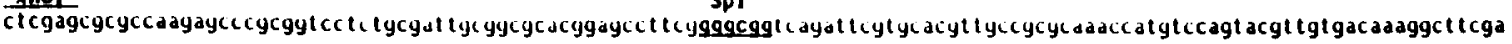

120

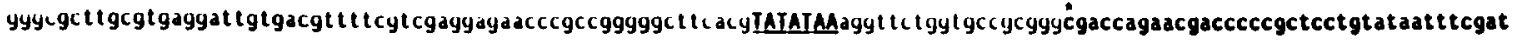

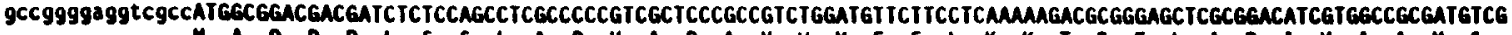

H A D D D L S S L A P V A P A V h h F F L K K T R E L A D J V A A K

240

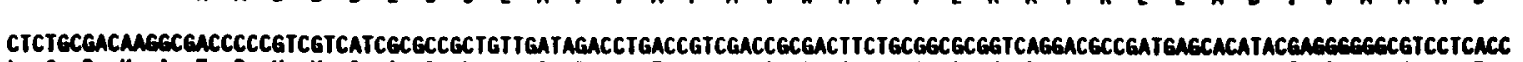
L C D K A T P V V I A P I L I D L T V D R D F C G A V R T P A S T Y E G G V L T

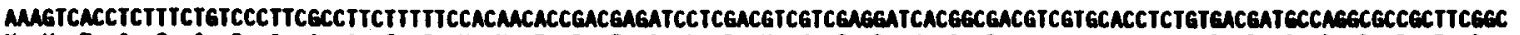
K V T S F C P F A F F F H T D E I L O V VE D H G O V V H L C O D A R R F G GTCCAGGCCIICAGTCCECTCGCTMATCGAGATCGCACGgACGTAGACGTCCTCTGCGACGAGCTAGGTATCGCCCCCGCCGAGTACACGGGGCACGTCGT6TGCGGAMCGGCCTCAAG

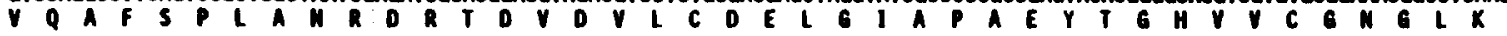
GACCTCCTCTACGCGEGECAGCTCATCCCCTGTCCCGAAGAGSCCGTGAGGTGCAGGTCGGCGCGGTCGATGGCGTCAAGGTCCCGCTCTATCCCTACACTCTCTTCTCCGGCCECGCC E L Y A G L I P P E E A K V O V G A V D G K Y P L Y Y T L F S G G

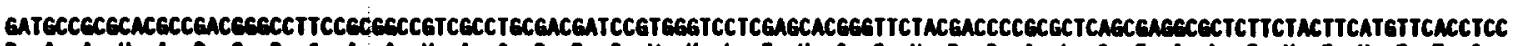
D A H A D G P S A V A C D D P M L E H G F Y D P A L S E A L F Y F M F T S

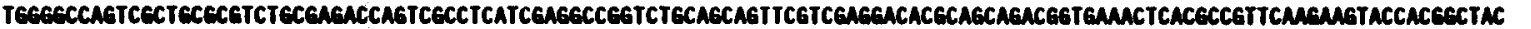
NG Q S L R V C E T S R L I E A G L Q Q F V E O T Q Q T Y K L T P F K K Y H E Y

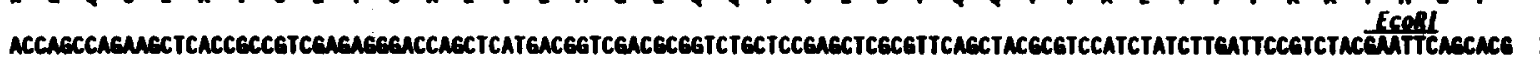

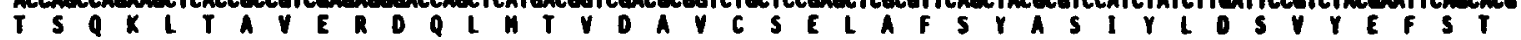

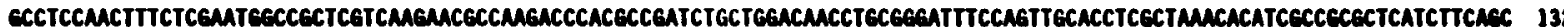

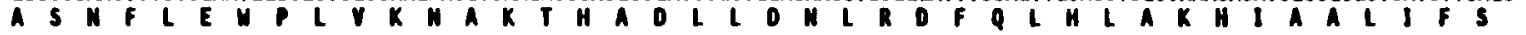

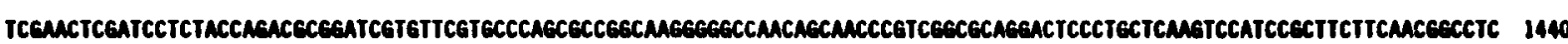
S N S I L Y Q T R I Y F Y P S A G K G A N S N P S A O D S L L K S I R F F N G L ACGGeCATGTACGATGACATCCTGMCGACGCCMGMaGACCATCAGGTICGAGGGGGCCGTCGGGCGGGACGAGMGTACTCCCCGCACCACCTECCCTACTTCTECGGCACCTCCCCE 15.0 T 6 H Y D D I L N D A K K T J R F E G A V G R D K Y S P H H L A Y F C G T S P

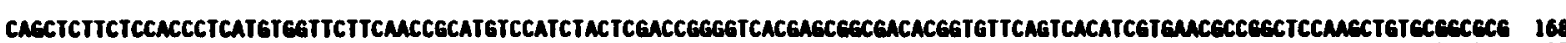

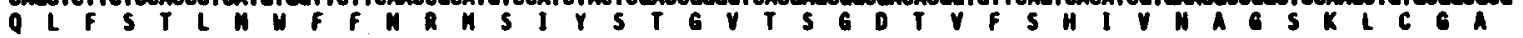

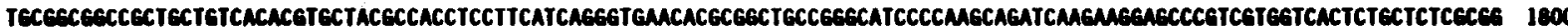
C 6 G C C H T C Y A T S F I R Y T R L P G I P K A K K E P V V T L L S R S15

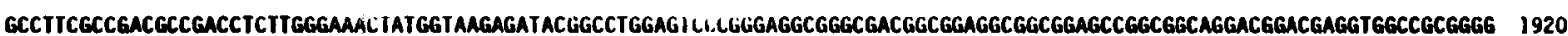

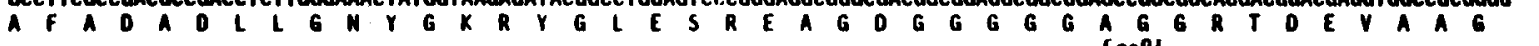

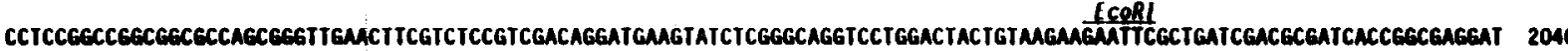
P P A G A S L L H F S Y O R K Y L G Q Y L D Y C K K N S L I D A I T G E D

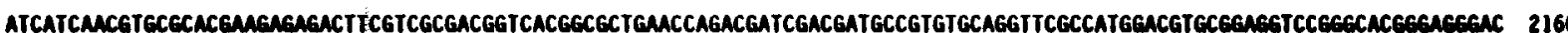

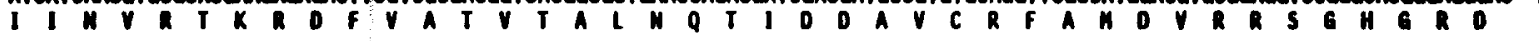
GAGATCAGCGGGASCACGCAGTCCTICAACCTGGACCTCAGCCCCTACECCACGGCCTICTCCCCCGTCCTGTCGITCCAGTATTACCGGACCATGTTCTCCATCATCCAGACCTEECC 2280

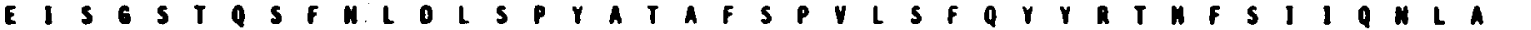
CTCATCACECCECGTCGTACGTEGTCGACACCCCCCTGACGACGGCGCAGATCTCCMAGTGGGTGACGCTGCACTICCAGTCCATCTECGGCGCGTTCGGGACGACGCCCCTCAMCNAS 2400 L I A A S Y V D H P L T A Q I S K W V T L H F O S I C G A F G T T L K K TIS

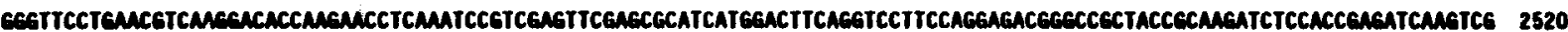

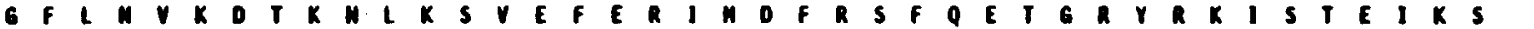
155 (nDeP)

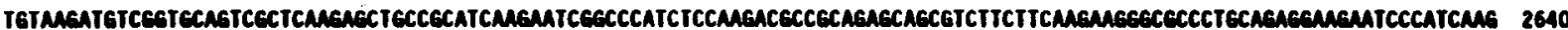

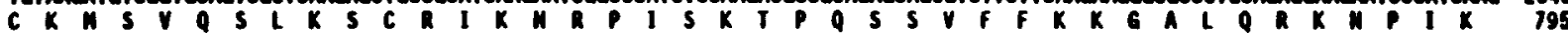

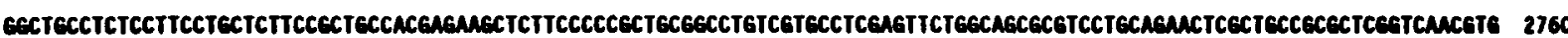

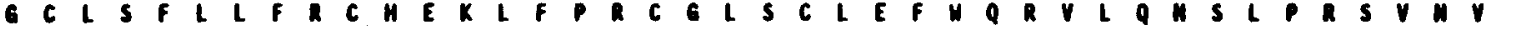
836 (1DOP) CECMGCTCGACGACTTCGACMACCTCGTGCGCTTCCTCCTCACCGTCACC GACGACTACGACGAGAGCGACGTGGTGGACATCCAGCCGGACTGCCTCCTCACCTACGTCEACMACCEC 2880 G K V E D D D L R F L L T V T D D Y D E S D V V D I O P O C L L S Y VE R R

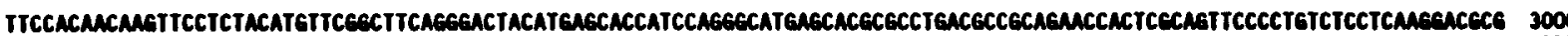

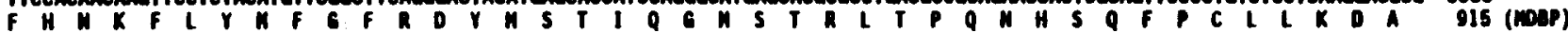

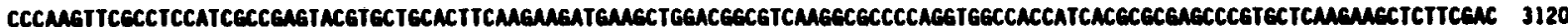
PKF A S I A E Y V L H F K K K L D G V K A Q V A T I T A E P V LKK L F D

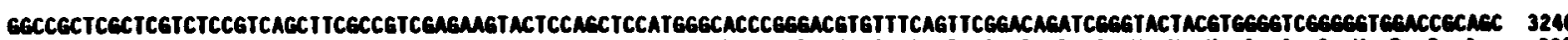

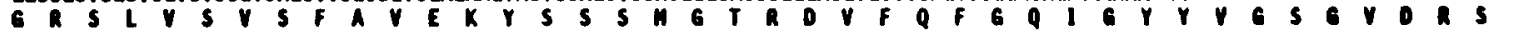

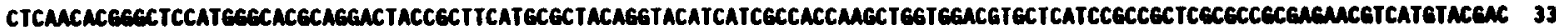

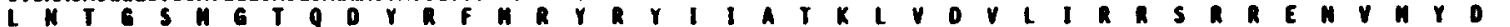

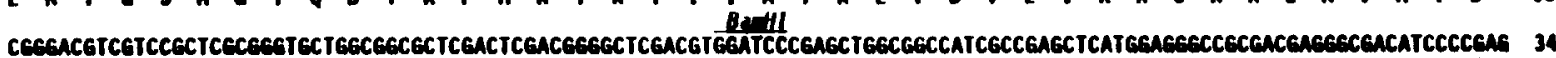

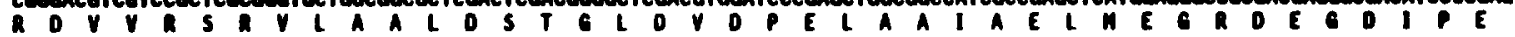

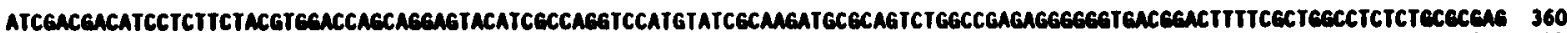

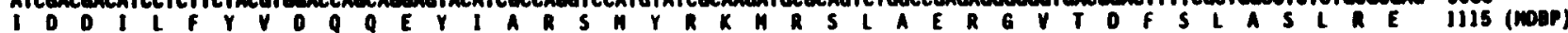


GCGACCGCCACCAACGCGACGGCGGCGGGCICCGCIGCTGGCGGIGGCGGCTCGGCGACGGAGGGCGGIGGCGGIGGGGCGGCCGCGGACGAGAGCGGTCCCATGTACGATITCTCCGCT 3720

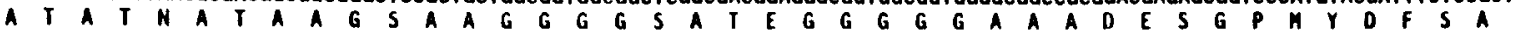

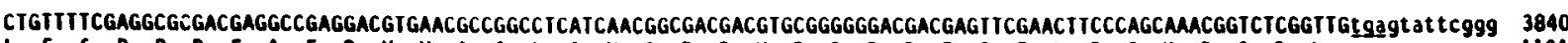
I F S R R D E A E D V N A G L I N G D D V R G D D E F E 55 (MDBP) acctccecgccccctcgactcct tctcctttccegtccgccgctcgtccggcgagcgggcgeccetttcIAIIMAagctcgttgaaatcácygtgtaacgtagcggtgtctgtatcgccg 3960

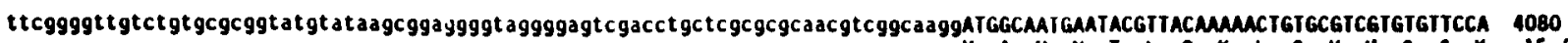
H A N T L Q K L C V V C S K IS (I18.5)

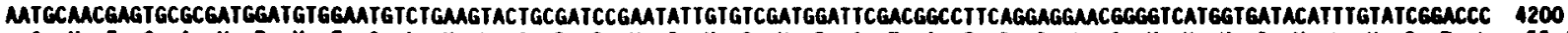
C NE C A H D V E C K Y C D P N I V S M O S T A F R R H G V V V I H L Y R T L S5 (118.5)

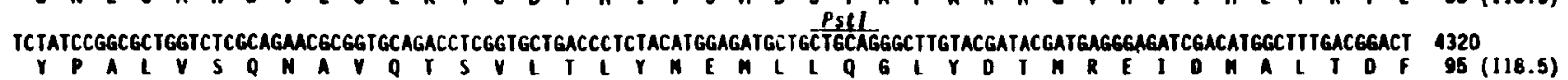

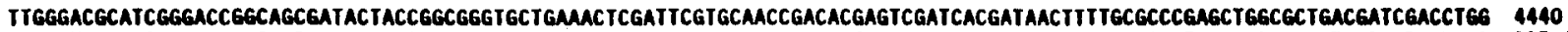
G T H R D R Q R Y Y R R V L K L D S C M R H E S I I I T I A P E L A L T I D L A $135(118.5)$

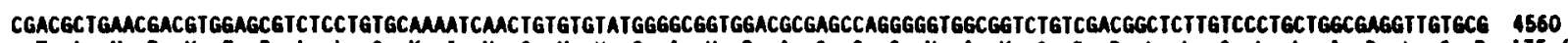

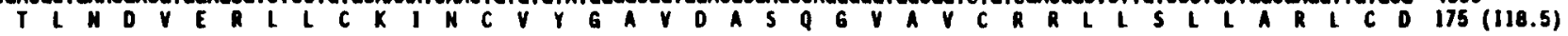

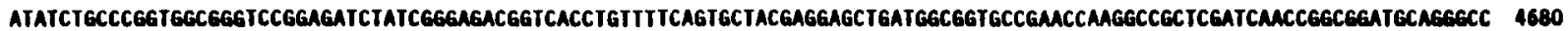

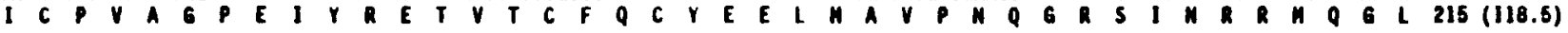

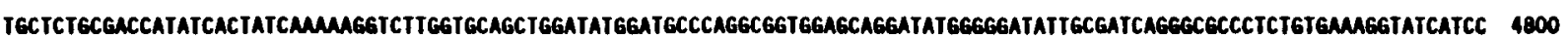

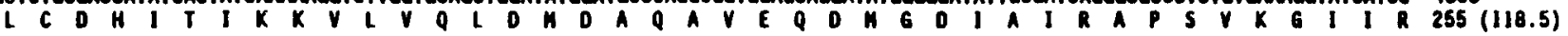

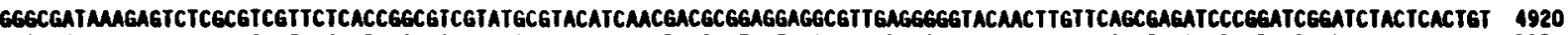
A I K S L A S F S P A S Y A Y I N D A E E A L R G Y N L F S E I P D R I Y S L S 295 (118.5)

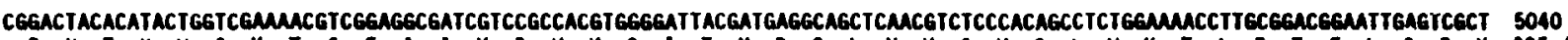
D Y T Y W S K T S E A I V R H V G I T N R G L N V S H S L H K T L R T E L S R Y 335 (118.5)

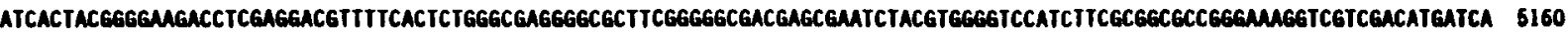
H Y G E D L E D V F T I G E G R F G G D E R I Y V G S I F A A P G K V V D A I T $375(118.5)$

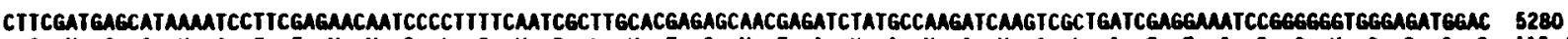
S I S I K S F E N M P L F N R L H E S N E 1 Y A K I K S

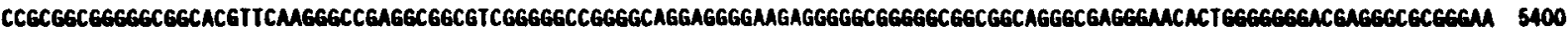
A A 6 A A R S A A E A A S G A GA G G E E GA GA A A G R G A T G G D E G A G T A55 (118.5)

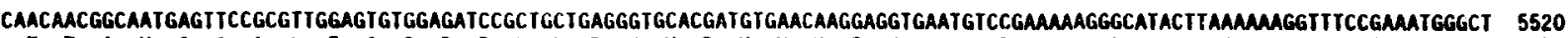
T T A I S S A L E C G D P L L R V H D V H K E V N V R K R A Y L K K V S E H G Y 495 (118.5) ACAACAMGGTATGGCCTGTATTCGAMCCAGGAGCALIGGTTACGAMACTGGTGAATGTCACCTGGTGGGAACGTGTGTTTGGAGGCGGTTTCCAMATTATGACGGTTITCTCT S64O H K V V H A A C I CCCGACAGCGGTCTATAATGAGGCCGAGACCTACCCCGACGTGGCCGAGAGCCTCGGCTACGACGACACCTCTATGTCATCAATMATCTCGTGCACAMGAGGCTCCCCTCCGAGCTGC 5760

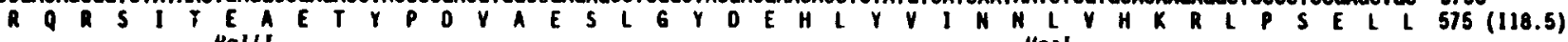

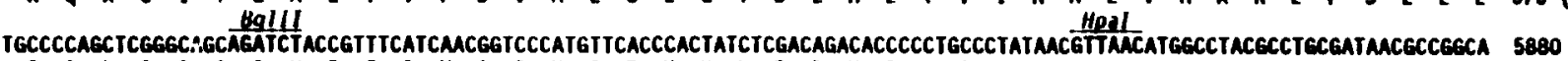

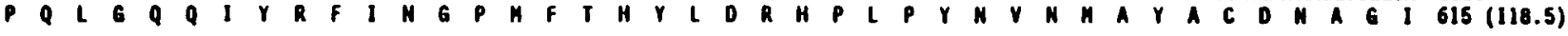

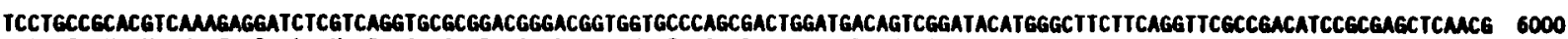

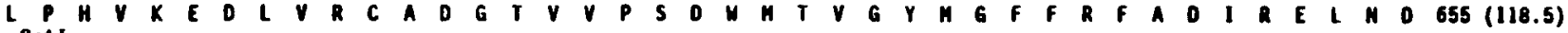

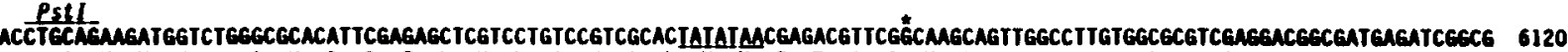

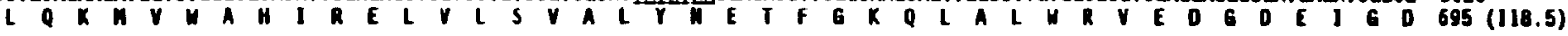

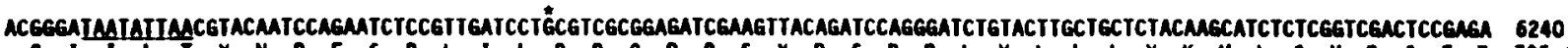

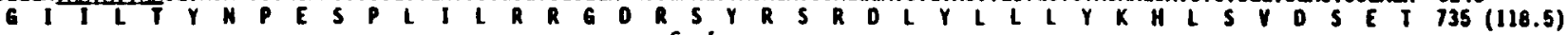

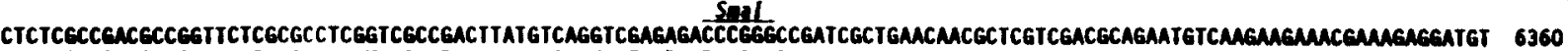

L A

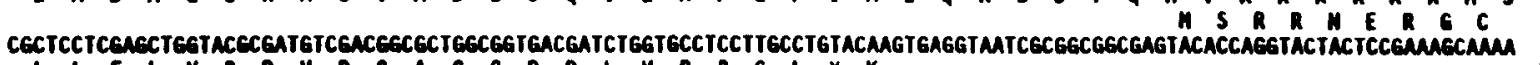

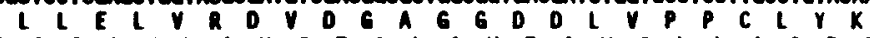

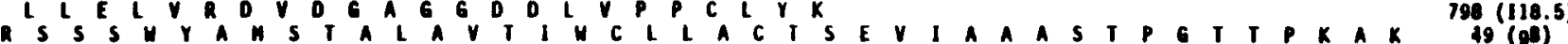

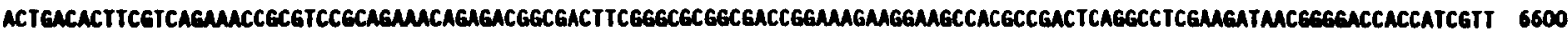
T $D$ T $S$ S 5 E T A S A E T E T A T S G A A T G K K E A

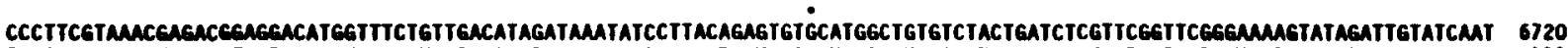

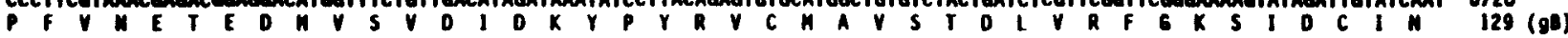

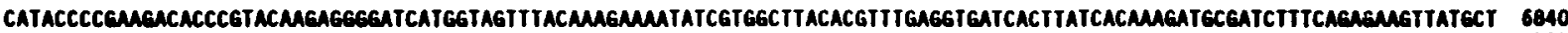
H T P K T P V Q E G I N V V Y K E M I V A Y T F E V I T Y H K D A I F Q R S Y A $169(0$.

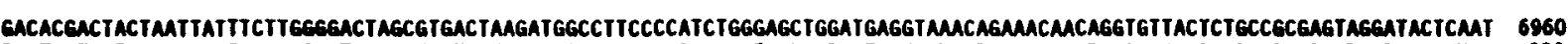

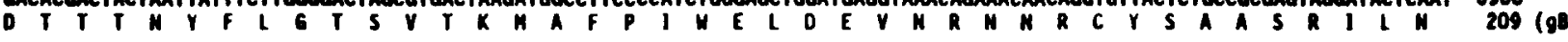

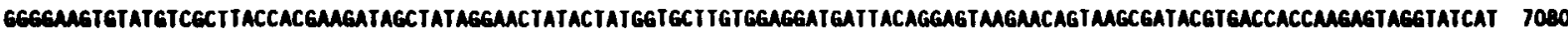
G E V Y V A Y H E D S Y Y R M

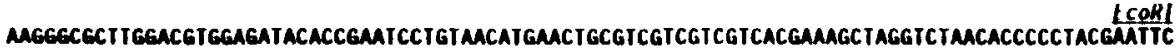

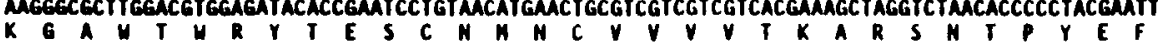




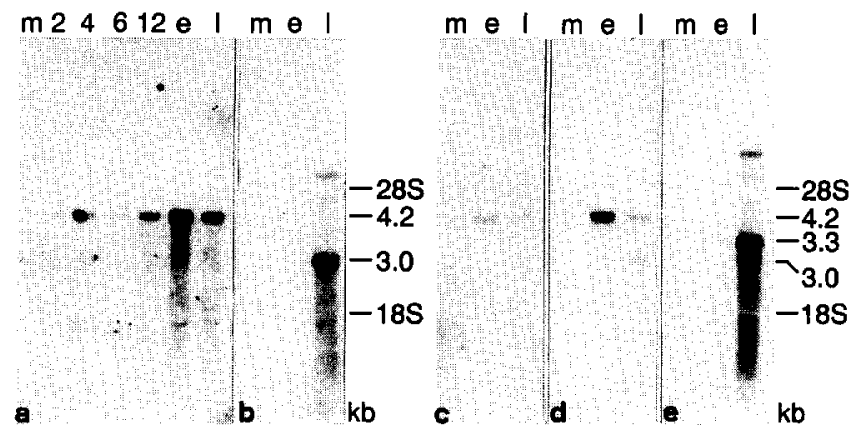

Fig. 3. Expression kinetics of the MDBP and ICP18.5 genes. Northern blot analysis with ${ }^{32} \mathrm{P}$-labeled DNA probes (for location of the probes see Fig. 1) was performed to determine the expression kinetics of the genes. MEF were mock infected $(m)$ or infected in the presence of PAA (e) or without inhibitors. Whole-cell RNA was isolated at 2, 4, 6, 12 (lanes 2 to 12), 20 (lanes e), and 24 (lanes I) hr p.i.

specific messages as they were seen with DNA probes located further downstream within the gB open reading frame (Rapp et al., 1992).

\section{Identification of the $5^{\prime}$ and $3^{\prime}$ ends of the MDBP and ICP18.5 transcripts}

Nuclease S1 protection experiments were performed to locate the ends of the transcripts. The $5^{\prime}$ end of the MDBP transcript was mapped with a 414-nt Xhol/Sall fragment (map units 0.401 to 0.400 ; Fig. $4 \mathrm{~A}$ (1)), which was $5^{\prime}$ end-labeled at the Sall site (Fig. 4B (1), lane 1). After hybridization of the probe to RNA isolated from cells in the early phase of infection and subsequent nuclease $S 1$ digestion a protected fragment of $215 \mathrm{nt}$ was seen (Fig. 4B (1), lane 3). The $5^{\prime}$ cap site of the MDBP mRNA is therefore located $215 \mathrm{nt}$ upstream of the Sall site (map units 0.400) at position 205 in Fig. 2. Thus, the MDBP mRNA has a short leader sequence of only $51 \mathrm{nt}$ in front of the first AUG. A putative TATA box was found $20 \mathrm{nt}$ upstream of the determined $5^{\prime}$ cap site (positions 180 to 185 in Fig. 2). The sequence GGGCGG at positions 56 to 61 represents a putative binding site for the transcription factor SP1. Nuclease $\mathrm{S} 1$ analysis with RNA from cells in the late phase of infection revealed the same protected fragment (Fig. $4 B(1)$, lane 4). Thus, the same transcription start site is used early and late in infection.

The $3^{\prime}$ end of the MDBP mRNA was determined with a 856-nt BamHI/Pstl fragment (map units 0.387 to 0.383; Fig. 4A (2)), 3' end-labeled at the BamHI site (Fig. 4 (2), lane 1). RNA from cells in the early and late phase of infection protected a fragment of $513 \mathrm{nt}$ from nuclease S1 digestion (Fig. 4B (2), lanes 3 and 4). Thus, the $3^{\prime}$ end is located at position 3930 in the nucleic acid sequence (Fig. 2), 99 nt downstream of the stop codon of the MDBP ORF. The sequence ATTAAA positions
3911 to 3916 ) $14 \mathrm{nt}$ upstream of the determined $3^{\prime}$ end could represent a polyadenylation signal of the rarely used type (Birnstiel et al., 1985). GT-rich sequences were found downstream of the $3^{\prime}$ end (positions 3932 to 3968). However, these sequences fit only weakly to the $3^{\prime}$ end consensus sequence YGTGTTYY (Birnstiel et al., 1985). Considering the size of the polyA-tail, the calculated size of $3726 \mathrm{nt}$ for the MDBP mRNA corresponds well to the observed size of $4.2 \mathrm{~kb}$ in the Northern blot hybridizations.

A 444-nt Notl/Sau3Al fragment (map units 0.386 to 0.384; Fig. 4A (3)), $5^{\prime}$ end-labeled at the Sau3Al site was used to map the $5^{\prime}$ end of the ICP 18.5 transcript (Fig. 4B (3), lane 1). The nuclease S1 analysis using RNA from cells in the late phase of infection revealed a protected fragment of $188 \mathrm{nt}$ (Fig. 4B (3), lane 3). Therefore, the $5^{\prime}$ cap site of the ICP18.5 mRNA is located $188 \mathrm{nt}$ upstream of the Sau3Al site at position 3941 in Fig. 2. Thus, the $5^{\prime}$ end of the ICP18.5 mRNA maps only $10 \mathrm{nt}$ downstream of the $3^{\prime}$ end of the MDBP mRNA. The length of the untranslated leader sequence of the ICP18.5 mRNA is $97 \mathrm{nt}$. The sequence TATTA at positions 3910 to 3014 (Fig. 2), 27 nt upstream of the $5^{\prime}$ cap site, could represent a TATA box. The sequence CCGCCC at positions 3846 to 3852 represents a putative binding site for the transcription factor SP1.

The sequence analysis revealed that the ICP18.5 and $\mathrm{gB}$ genes, and even the ORFs, overlap. Therefore, it was expected that the $3^{\prime}$ end of the ICP18.5 mRNA and the $5^{\prime}$ ends of the gB mRNAs are collinear. To determine the $3^{\prime}$ end of the ICP18.5 mRNA, DNA fragments were used, which were $3^{\prime}$ end-labeled upstream of the $5^{\prime}$ cap sites of the gB mRNAs. This experimental procedure should avoid misinterpretation resulting from hybridization and protection of the probes with the gB mRNA. A 1319-nt Hpal/EcoRI (map units 0.3766 to 0.371 ; Fig. $4 A(5))$ and a $1389-n$ t $B g / l / / E C O R I$ fragment (map units 0.377 to 0.371 ; Fig. $4 A$ (4)), $3^{\prime}$ end-labeled at the $\mathrm{Hpal}$ and at the Bg/ll sites, respectively (Fig. 4B, (4) and (5), lanes 1), were used. Protected fragments of approximately 820 and $900 \mathrm{nt}$ were identified following the nuclease $S 1$ digestion (Fig. 4B, (4) and (5), lanes 3). Thus, the ICP18.5 mRNA contains a trailer sequence of approximately $250 \mathrm{nt}$ downstream of the stop codon of the ICP18.5 ORF. To determine the $3^{\prime}$ end of the ICP 18.5 mRNA more precisely, the ICP18.5 mRNA was reverse transcribed using the primer (dT)17-R1-R0, and the $3^{\prime}$ end of the cDNA was amplified using primers End1 and Ro according to the method of Frohman et al. (1988). A 300bp fragment was identified following amplification and subcloned into pUC19. Sequence analysis located the $3^{\prime}$ end of the ICP18.5 mRNA to position 6665 in Fig. 2. 
A

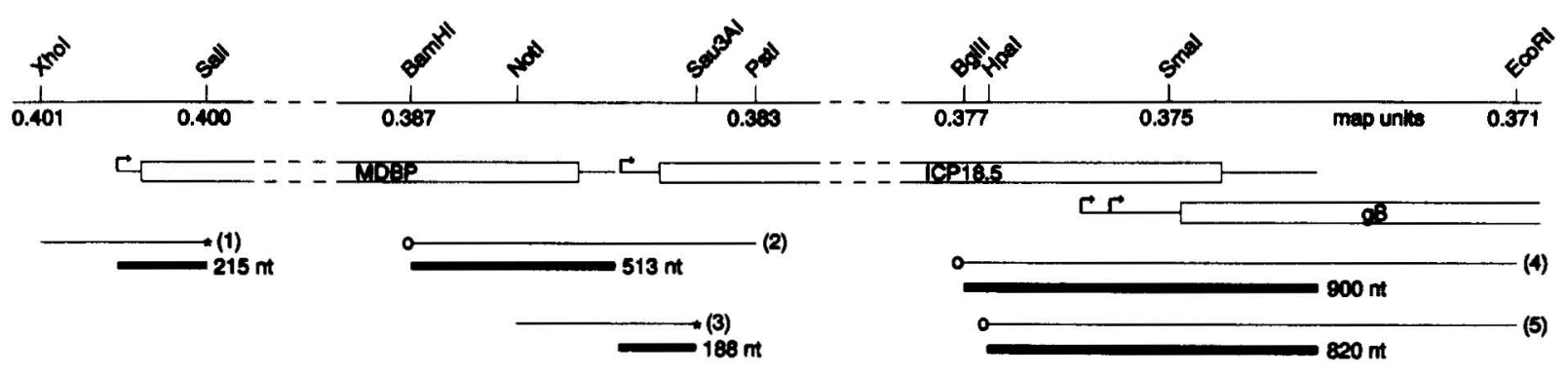

B

(1)

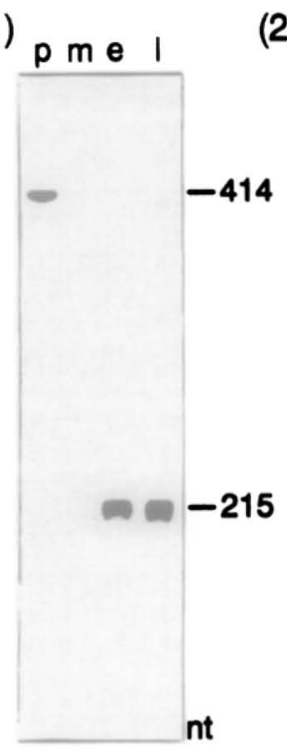

(2)

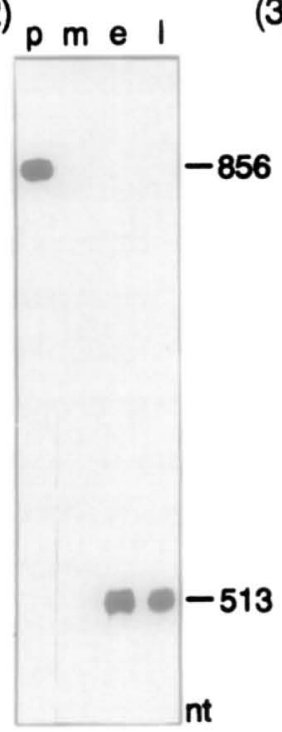

(3)

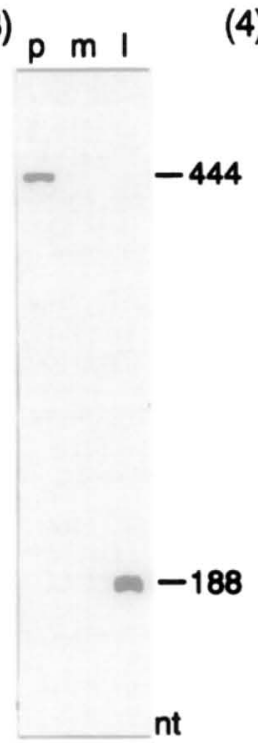

(4)

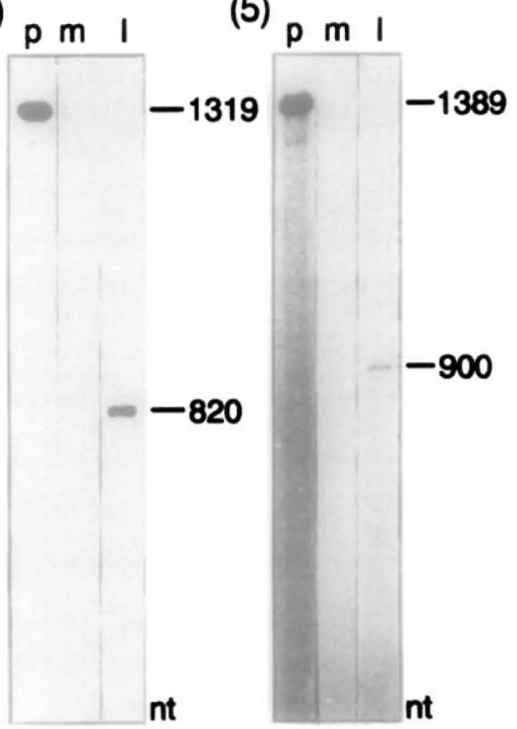

FIG. 4. Localization of the $5^{\prime}$ and $3^{\prime}$ ends of the MDBP and ICP18.5 mRNAs. (A) Experimental design; (B) experimental data. (A, top) Cleavage sites of restriction enzymes, which were used for preparation of the probes are indicated above the open reading frames (open bars) and the deduced structure of the mRNAs. Gaps were introduced ( - - ) into the drawing to present all relevant information in one picture. (A, bottom) $5^{\prime}$ $\left({ }^{*}\right)$ and $3^{\prime}$ end-labeled DNA fragments $\left(\mathrm{O}_{-}\right)$were hybridized to whole-cell RNA and then digested with nuclease S1. Solid bars and numbers indicate the location and length, respectively, of the protected fragments. (B) Autoradiographies of protected fragments separated by electrophoresis in $6 \%$ (experiments (1) and (3)) or $4 \%$ denaturing polyacrylamide gels (experiments (2), (4), and (5)). Lanes p show the labeled fragments before the nuclease treatment, and lanes $\mathrm{m}$, e, and $\mathrm{l}$ show the nuclease-resistant fragments after hybridization either to RNA from mock-infected cells, or to early RNA isolated $20 \mathrm{hr}$ p.i. from cells which were infected with MCMV in the presence of PAA or to late RNA isolated from MCMV-infected cells $24 \mathrm{hr}$ p.i. Size markers were $5^{\prime}$ end-labeled Hpall cleavage products of pBR322 and the 123-bp and 1-kb ladders (GIBCO $B R L)$.

An $A \sqrt{T}$-rich sequence was found $14 \mathrm{nt}$ upstream of the determined $3^{\prime}$ end (ATAAATAT; positions 6644 to 6651), which does not represent a typical polyadenylation signal, whereas the sequence TGTGTCT (positions 6672 to 6678) 6 nt downstream of the determined $3^{\prime}$ end shows a partial homology to the $3^{\prime}$ consensus sequence YGTGTTYY (Birnstiel et al., 1985). The calculated size of $2725 \mathrm{nt}$ for the ICP18.5 transcript is in accordance with the observed size of $3.0 \mathrm{~kb}$ for the ICP18.5 mRNA in the Northern blot experiments if the increase in size by polyadenylation is taken into account.

\section{Amino acid sequence conservation between the MCMV MDBP and the homologous proteins of HCMV, EBV, and HSV-1}

The amino acid sequence of the MCMV major DNA binding protein was deduced from the nucleic acid sequence of the identified open reading frame. The MDBP ORF is capable of encoding a polypeptide of 1191 amino acids (Fig. 2), and the calculated molecular mass of the MCMV MDB protein is $131.7 \mathrm{kDa}$.

The amino acid sequence of the MCMV MDB protein was compared by the Genetic Computer Group 
1 MADDDLSSLAPVAPAVUMFF́FKKTRELADIVAAHSLCOKATPYVIAPLLIDLTVOROFCGAVRTPMSTYEGGVLTKYTSF

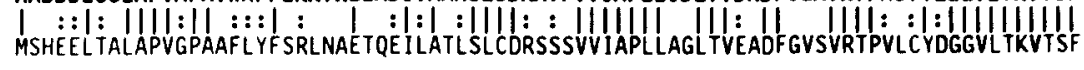

81

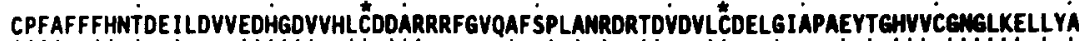

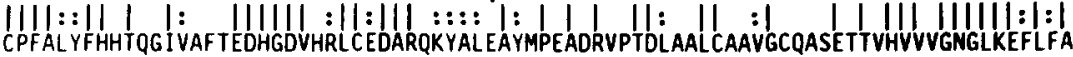
GQLIPCPEEAVKVQVGAVDGVKVPLYPYTIFSGGADAAHIDOGPSAAVACDOPUVLEHGFYOPALSEALFYFHFTSWEQSi

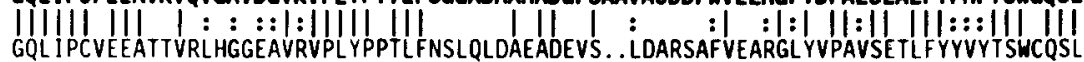

241 RVCETSRLIEAGLOQFYEDTOQTVKLTPFKKYHGYTSOKLTAVERDQLMTVOAVCSELAFSYASIYLDSVYEFSTASMFL

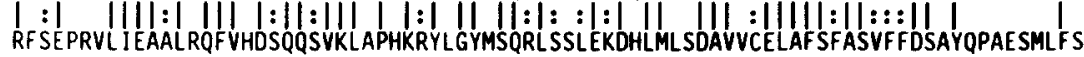
RFSEPRVLIEAALROFVHDSQQSVKLAPHKRYGMIQRLSSLEKDHLMLSOAWVELAFSFASVFFDSAYQPAESMLF ENPLYKNAKTHADLLDNLROFQLHLAKHIMLLIFSSHSI IYYTRIVFYPSACKGANSMPSA. COSLLKSIRFFNGLTEMY |111| || | ||: | :: ||| |:|||:|| ||:||| |:|::|:: :1 |::||| | | ||1:: WPLVTNATOHRDL IRAL TELKLHLSTHVAALVFSANSVLYQHRLVYLQSSARHPSAGGTASQETLLKAIQFTNGL SAAC

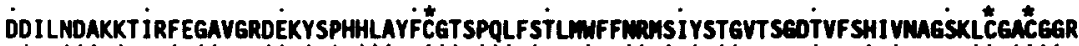

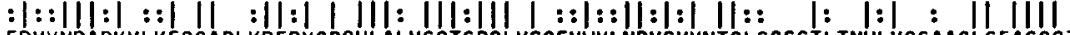
EDVYMDARKVLKF QGAPLKDERYGPQHLALVCGTCPQLVSGFVWYLNRVSVYNTGLSGSSTLTNHLVGCAAGLCEACGGT CCHTČ́YATSF IRVNTRLPGIPKOIKKEPYVYTLLSRAFADADLLEMYGKRYGLESREAG......... DGGGGGAGGR. ||||||$|:||||||:||||||||:|:||:||:||:|:||:::::| \quad||:||:|| \mid$ CCHTCYQTAFVRVRTRLPVVPKQPKKEPCVITVOSRFLNDVDILGSFGRRYMVDAKOGGLDGKGDDGVPGGGAGGGGGRD 558

549 .....TDEVMAGPPAGGA. .S6....... LNFVSVDRAKYLGQVLOVCKKMSLIDAITGEDIINVRTKRDFVATVTALM $:|:::|:||:|| \quad:|||||:|||||||||:||||:$ : | ||||:||| VSGGPSDGLGGGRGGGGGDSGGMMGRGGRMLGASVDRTYRLNRILDYCRKMRL IDPVTGEDTF SAHGKSDFVAVFSALN 638

614 QTIDO.AVCRFAMDVR.RSGHGRDEISGSTQSFMLDLSPYATAFSPVLSFQYYRTMFSI IQMLALIMA ISYYVDNPLTTA $:|||:|:||:||||:|||||||||||||:|:|:|::|:|||:||||||:|||||| \mid$ KFVDOEALG. FUSEVRLKS. .SRDEVAGATOAFNLDL NPYAVAFOPLLAYAYFRSVFYVIONVALITATSYIVDNPLTIN 715 QISKWVILHFQSICGAFGTTPLKKGFLMVKDTKMLKSVEFERIMDFRSFQETGRYRKISTEIKSCKMSVQSLKSCRIKMR

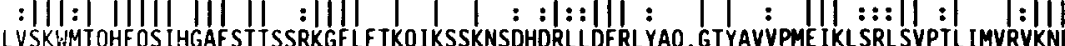

772 PI... SKTPQSSVFFKKGALQRKKN IKGCLSFLLFRCHEKLFPRCGLSCLEFIQRVLQNSLPRSWWGKVEDFONLVRFL

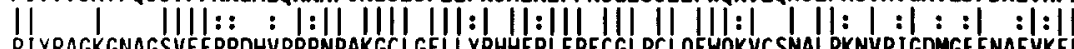

349 LTVTDOYDESOVVDIQPOCLLSYYENRFHAKFLYMFGFRDYHST IQGHSTRLTPQNHSQFPCLLKOAPKFAS IAEYVLHF $:\|\||||::|:|||:|||||||||||:\|:\|:::|::||||||||||:||:||||:| \mid$ VAVIADYQEHDLL DVAPOCVL SYVESRFHNKFLCYYGFKDYIGSLHGLTTRL TTONHAOF PHVLGASPRFSSPAEFALHV 954 KKMKLDGVKAPQVATITREPYLKKLFDGRSL VSVSFAVEKYSSSMGTRDVFQFGQIGYYVGSGVDRSLNTGSHGTQOYRF $|:|$ || || ||: || :::: : : |||:| |||| :::::|||||||: | ||$:|||||||||| \mid$ KGLKIAGVPAPMAATVARESL VRSVF EHRSLVTVPVSVEKYAG INNSKE I YQFGOIGYF SGNGVERSLNVSSMSGODYRF 1034

1009 MRYRYIIATKL VOVLIRRSRREMYMYOROVVRSRVLAALDSTGLDVDPELAMIAELMEGRDEGDIPEIDOILFYVDQQEY

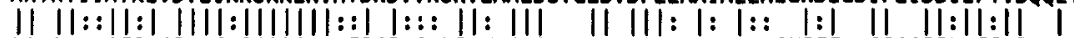
MRQRYLLATRLADVL IKRSRRENVLFDADLIKNRVMLALDAENLDCDPEVMAVYEIISVREE. IPASDDVLFFVGCEA 1112 IARSMYRKMRSLAERGVTOFSLASLR. . EATATHATAAGS......... MGGGGSATEGGGGGAMADESGPHYDFSA

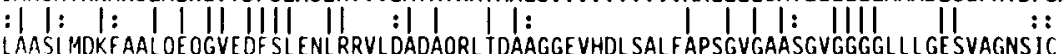




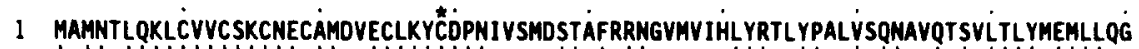

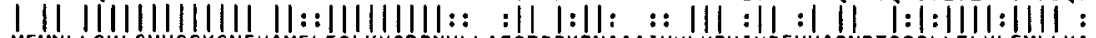
MEMNLL QKLCVVCSKCNEYAMELECLKYCDPNVLLAESTPFKRNAAA IVYLYRK IYPEVVAQNRTOSSLLTLYLEMLLKA 80

81 LYOTMREIDHALTOFGTHRDRORYYRRVLKLDSČ゙RHESITITFAPELALTIDLATLMOVERLLCKIMCVYYGAVDASQGV $1::|||:||:||||:|||||:::|::::||||||||:|||:||||: \mid:$ LHEDTALLORALMAYSRQPORAAFYRTVLRLORCDRHHTVELQF TONVRF SVSLATLNOIERF LCKMNYYYGILAPEAGL 160

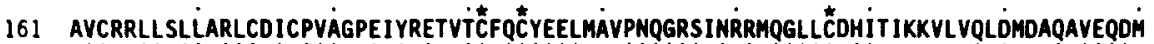

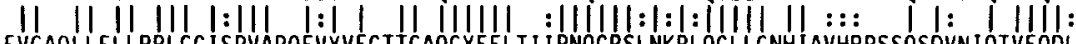
EVCAQLLELLRRLCGISPVARQEVYVEGTTCAQCYEELTIIPNQGRSL NKRLQGLLCNHIAVHRPSSQSOVNIQTVEQOL 240

241 GDIAIRAPSYVKGIIRAIKSLASFSPASYAYINDAEEALRGYMLFSEIPDRIYSL SDYTYYSSKTSEAIVRHYGITMRQL $\dot{M V}$ $|:||:|::|:||||||||1::||||||||||::||:|||||||:||||:|||||1::|||:|||| \mid$ LDLTTRIPHLAGVLSALKSLF SSSSAYHSY IQEAEEALREYNLFTDIPERIYSLSOFTYWSRTSEVIVKRVG ITIQQLNV 320

321 S̈HSLWKTLRTEL SRYHYGEDLEDVFTLGEGRFGGOERIYVGSIFAAPGKVVDMITSMSIKSFEMNPLFNRLHESMEIYAK

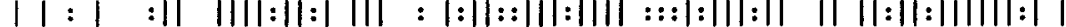
YHQLCRAL MNG ISRHL YGEOVEDIFVLGEKALDGEERMFVGSVFAAPNRI IDL ITSL SIQAFEDNPVFNKLHESNEMYTK 400

401 GVGOGPAGGAARSRA. EAASG. AgaGgeEgagaAagrGnTGgDE

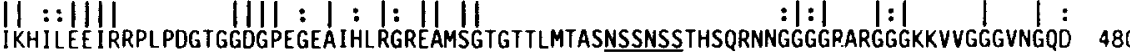

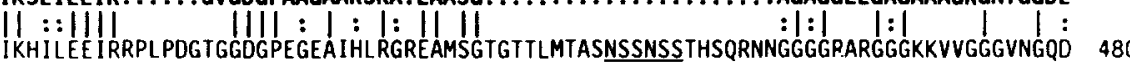

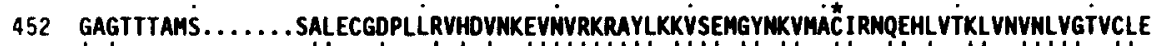
| :::: ||: |:| |:|||||||||| ||||:|| ||: ||: ||:|:||: ||||| :||: GDGSENGLRVRNCDEHEALDL VOARSR IHNVTREVNVRKRAYLQKVSEVGYGKVIRC IKTQERL TSKL IDVNLVGPLCLO 560

525 AVSK IMNGGLLSR. QRS ITEAETYPDVAESLGYDEHLYVIMHLVHKRLPSELLPQLGQQOIYRF IMGPMFTHYLDRHPLPYN $: \|:||||||:: \quad||:::|||||||:||:||||||||||||:|||:||||||||$ FISKLMNGFLYRSO. YHQDQDVV. DVGDQFTYYEELYYVNNLIHKSLPVESLPLLGQQIYELCNGPLFTHCTDRYPLSHN 638

604 VNMAYACONAGILPHVKEDLVRCADGTVUPSDWMTVG YMGFFRFADIRELMOLOKMVYAHIRELVLSVALYMETFGKQL.

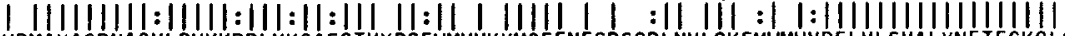
VDMAYACDNAGVLPHVKDDL VKCAEGTVYPSEWMVVKYMGFFNFSDCQDLNVLQKEMWMHVREL VL SVALYNETRGKQLS 718 .ALHRVE...DGOEIGDGI ILTYMPESPLILRRGORSYRSRDLYLLLYKHLS....... VDSETLADAGSRASVADLCQV

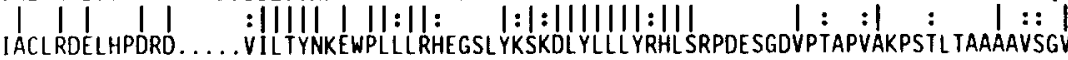
793 ERPG.....PIAEQRSSTQNV........KKKRKRHSLLELYVRVYD.GAGGDOLYPPCLYK

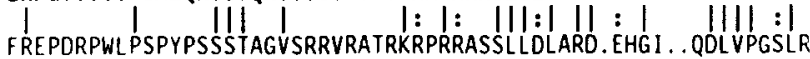

FIG. 6. Alignment of the amino acid sequences of the MCMV ICP18.5 and the HCMV UL56 proteins. Labeling is as described in Fig. 5. Putative $\mathrm{N}$-glycosylation sites (NXS/T) are over- or underlined.

quence (not shown). Similar gaps have been observed previously, when the simian CMV and HCMV MDBP sequences were compared (Anders, 1990). Thus, we conclude that the HCMV MDB protein contains an insertion of 26 residues at this position compared to the MCMV and SCMV MDB proteins (Anders, 1990) and to HSV-1 ICP8. 16 of the 27 cysteine residues are located at identical positions in the MCMV and HCMV MDBP amino acid sequences.

The MCMV and EBV MDBP amino acid sequences show a significant degree of conservation represented by $50 \%$ identical and similar amino acids (Fig. $7 \mathrm{~b}$ ). The similarity between the sequences of the MCMV MDBP and HSV-1 ICP8 protein is 45\% (Fig. 7c). Six cysteine residues in the MCMV MDBP are at identical positions as in the HSV- 1 ICP8 sequence (amino acids 107, 134 , $431,473,476$, and 484), and the same number of cysteine residues is conserved to the EBV MDBP sequence (amino acids 107, 295, 473, 476, 484, and 705). Three of these conserved cysteine residues (positions 473,476 , and 484 ) are located within a motif which has been implicated with DNA binding and could perhaps fold into a zinc finger structure (Gao et al., 1988).

Amino acid sequence conservation between the MCMV ICP18.5 protein and the homologous proteins of HCMV, EBV, and HSV-1

The MCMV ICP18.5 ORF is translated into a polypeptide of 798 amino acids (Fig. 2). The calculated molecular mass of the MCMV ICP18.5 protein is $89.1 \mathrm{kDa}$.

Analogous to the comparison of the MDB proteins, the amino acid sequence of the MCMV ICP18.5 protein was compared to the sequences of the HCMV UL56 protein (Figs. 6 and 7d), the EBV homolog (BALF2) (Fig. 7e), and the HSV-1 ICP18.5 protein (Fig. 7f). The amino acid sequences of the MCMV and HCMV ICP18.5 proteins display $74.4 \%$ similarity. Four hundred forty amino acids are identical (55\%) and 133 residues are replaced by conserved residues (Fig. 6). There are again gaps in the alignment between amino acids 409 and 461 , which result from additional residues in the HCMV UL56 sequence. Only the carboxy 

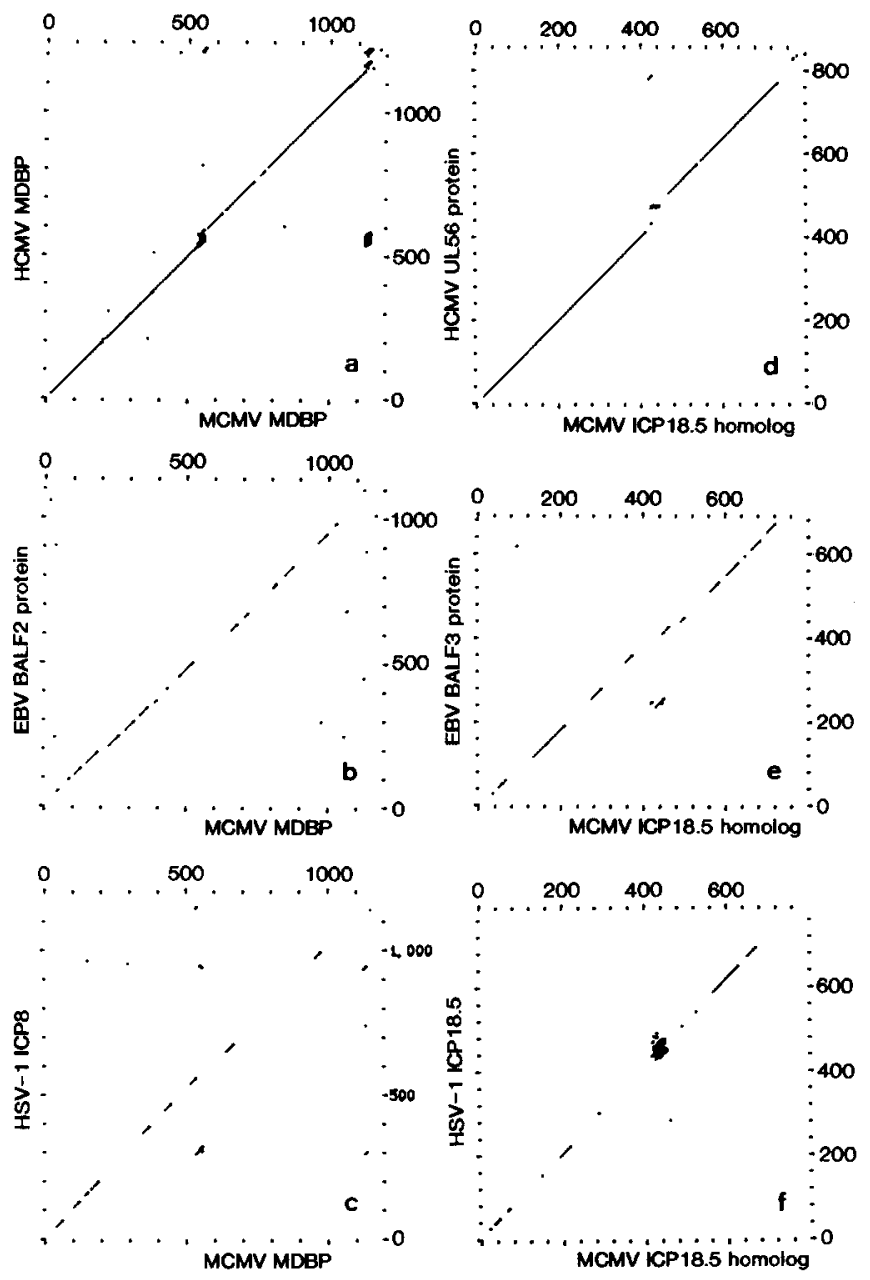

FIG. 7. Dot matrix comparison of the MCMV MDB protein $(a, b, c)$ and the ICP18.5 homolog $(d, e, f)$ to the homologous proteins of HCMV, EBV, and HSV-1. The following parameters were used: window, 30 aa; and stringency, 18 aa. The $\mathrm{N}$ termini of the sequences are in the bottom left corner in each graph.

terminal amino acids (the last 68 residues) are less conserved. According to the same criteria, the similarity between the amino acid sequences of the MCMV ICP18.5 protein and the EBV homolog is $51 \%$ (Fig. 7e), and the similarity to the HSV- 1 ICP 18.5 protein is $49 \%$ (Fig. 7f). Whereas the similarity between the MCMV ICP18.5 and the EBV BALF3 protein is equally distributed throughout the complete sequence (Fig. 7e), the comparison to the HSV-1 ICP18.5 sequence shows a higher conservation of carboxy-terminal sequences (amino acids 574 to 669 ; Fig. 7f). Sixteen of the 22 cysteine residues in the MCMV ICP18.5 sequence are at identical positions as in the HCMV UL56 sequence and 6 cysteine residues are conserved in comparison with the HSV-1 ICP18.5 (amino acids 29, 114, 191, 194,217 , and 501) and with the EBV BALF2 sequence (amino acids 29, 191, 194, 217, 501, and 610). Only two potential $\mathrm{N}$-glycosylation sites (NXT/S) were identi- fied in the MCMV ICP18.5 sequence (positions 319 to 321 and 675 to 677), whereas 6 and 3 glycosylation sites were found in the HCMV UL56 and HSV-1 ICP18.5 sequences, respectively. The sequence KKKRKR (amino acids 768 to 773 ) at the end of the MCMV ICP18.5 amino acid sequence represents a consensus nuclear targeting sequence.

\section{DISCUSSION}

In this communication we report on the nucleotide sequence of the MCMV genes encoding the major DNA binding protein and the ICP18.5 homolog. The expression kinetics of the genes was analyzed and the $5^{\prime}$ and $3^{\prime}$ ends of the mRNAs were determined. The homology of the MCMV MDB and ICP18.5 proteins to the respective proteins of other herpesviruses is shown.

The genes encoding the viral DNA polymerase, the glycoprotein B, a putative assembly protein and the major DNA binding protein constitute a gene block, which is conserved throughout all herpesviruses (Kouzarides et al., 1987). In MCMV, only two genes of this block, the DNA polymerase and glycoprotein B genes, had been identified so far (Elliott et al., 1991; Rapp et al., 1992). We have now analyzed the region upstream of the gB gene and found the MCMV genes encoding the MDB protein and the ICP18.5 homolog. Thus, the organization of this gene block in MCMV exactly mirrors the situation in HCMV.

The MCMV MDBP gene encodes a protein of 1191 amino acids with a predicted molecular mass of 131.7 $\mathrm{kDa}$. The HCMV strain AD169 MDB protein consists of 1235 amino acids (Chee et al., 1990) and the apparent molecular masses of the MDB proteins of simian (strain Colburn) and human CMV have been determined to 129 and $140 \mathrm{kDa}$ (Anders et al., 1986; Kemble et al., 1987). Thus, the predicted molecular mass of the MCMV MDB protein is in the same range as the observed molecular masses of the SCMV and HCMV MDB proteins.

The highest degree of similarity was observed between the amino acid sequences of the MCMV and HCMV MDB proteins. However, the similarity to the amino acid sequences of the HSV-1 and EBV MDB proteins is remarkable. This conservation points to the important function of the MDB proteins. For the HSV-1 ICP8 protein it has been shown that it is essential for the replication of the viral DNA (Wu et al., 1988). It is assumed that the MDB proteins bind to and stabilize the single-stranded DNA immediately after unwinding of the double strand, thereby facilitating the entry of the viral DNA polymerase and the replication of the DNA (Wu et al., 1988). The conservation between the MDB 
proteins of so distantly related herpesviruses as HSV1, EBV, and the CMVs shows that at least for some domains only subtle changes are allowed in order to preserve the function of the protein.

A 4.2-kb mRNA has been identified which originates from the MCMV MDBP gene and which has the capacity to encode the MDB protein. The expression kinetics of the MCMV MDBP gene is consistent with the function of the MDB protein. In HSV-1 it was shown that the ICP8 protein migrates to prereplicative sites prior to DNA replication (Gao and Knipe, 1989), and it was proposed that ICP8 serves as organizational protein for targeting other replication proteins to these sites (Quinlan et al., 1984). For the HCMV and SCMV MDB proteins a subnuclear localization was observed which is reminiscent of the HSV-1 ICP8 protein (Anders et al., 1987; Kemble et al., 1987). Whether the MCMV MDB protein has a similar function and shows a similar subnuclear compartmentalization awaits the production of a specific antiserum and further analyses.

The size of the MDBP mRNA is in accordance with the determined $5^{\prime}$ and $3^{\prime}$ ends of this mRNA and is sufficient to encode a 1191 amino acid polypeptide. Transcripts of similar sizes $(3.9$ and $4.5 \mathrm{~kb}$, respectively) were detected for the SCMV and HSV-1 MDBP genes (Anders and Gibson, 1988; Rafield and Knipe, 1984). However, one additional transcript of $10 \mathrm{~kb}$ was found in SCMV and HSV-1 (Anders and Gibson, 1988; Rafield and Knipe, 1984) and in HCMV only a 10- to $12-\mathrm{kb}$ transcript arising from the MDBP gene could be detected (Kemble et al., 1987). In MCMV only the 4.2$\mathrm{kb}$ mRNA and no larger transcript was seen, even after long exposures of the Northern blot. Therefore, the transcriptional pattern of the MCMV MDBP gene is slightly different from that of the other CMV MDBP genes.

A putative TATA box was found immediately upstream of the determined $5^{\prime}$ cap site of the MDBP mRNA. The determined $3^{\prime}$ end of the MDBP mRNA and the $5^{\prime}$ cap site of the ICP 18.5 mRNA are only separated by $10 \mathrm{nt}$. Thus it is obvious that the $3^{\prime}$ end of the MDBP gene and the promoter of the ICP18.5 gene overlap and it is difficult to dissect the termination signals for the MDBP mRNA from promoter consensus sequences of the ICP18.5 gene. For example, it remains open whether the sequence TATTAAA (positions 3910 to 3916) constitutes a TATA box for the ICP18.5 gene or it represents an atypical polyadenylation signal (Birnstiel et al., 1985) for the MDBP mRNA. Putative binding sites for the transcription factor $S p 1$ were found 144 and 89 nt upstream of the $5^{\prime}$ cap sites of the MDBP and ICP18.5 mRNAs. This proximal location of $\mathrm{Sp} 1$ binding sites is typical for a series of cellular and viral promoters.
The amino acid sequences between the MCMV ICP18.5 protein and its homologs are as highly conserved as the sequences of the MDB proteins and of the glycoproteins B (Rapp et al., 1992). The function of the HSV-1 ICP18.5 protein and its homologs in other herpesviruses was unknown for a long time and has not been completely unraveled until now. Previous analyses with temperature-sensitive HSV-1 mutants pointed to a function in the transport of glycoproteins to the membrane (see for example Pancake et al., 1983). However, recent studies suggested a function of the protein in virus assembly (Addison et al., 1990). This is consistent with a nuclear localization of the Pseudorabies virus ICP18.5 protein (Pederson and Enquist, 1991). The amino acid sequence of the MCMV ICP18.5 protein is not indicative for a particular function of the protein. No typical transmembrane region was found and the sequence contains only two potential N-glycosylation sites. Therefore, a transport of the protein to the cell membrane and glycosylation of the protein appears quite unlikely, whereas the putative nuclear transport signal of the MCMV ICP 18.5 protein suggests a nuclear location of the protein.

An interesting feature of the MCMV ICP18.5 gene is the overlapping of the ICP18.5 and $\mathrm{gB}$ open reading frames. A similar overlap or at least a close spacing of the ICP18.5 and gB ORFs was also found in other herpesviruses (reviewed in Pederson and Enquist, 1991). Thus, the promoter of the gB gene is located within the coding region of the ICP18.5 gene. The $3^{\prime}$ end of the MCMV ICP18.5 mRNA was mapped within the ORF of the $\mathrm{gB}$ gene. This is different from the situation in HSV1 where a $3^{\prime}$ collinearity of the ICP 18.5 and gB transcripts was found and the usage of the same polyadenylation signals for both transcripts is likely (Holland et al., 1984). It is an intriguing question how the transcriptional machinery terminates the MCMV ICP18.5 mRNA when at the same position a readthrough of the gB gene occurs. It is possible that the untypical polyadenylation and $3^{\prime}$ end consensus sequences of the MCMV ICP18.5 gene play a role in ICP18.5 mRNA termination and $\mathrm{gB}$ transcription.

The gene block encoding the MDBP, the ICP18.5 homolog, $\mathrm{gB}$, and the DNA polymerase represent the most conserved region in the herpesviral genomes (Kouzarides et al., 1987). All four genes have now been characterized in MCMV (Elliott et al., 1991; Rapp et al., 1992). In the two CMV genomes the spatial relationship of the genes is identical. The conservation between the amino acid sequences of the encoded MCMV and HCMV proteins is striking, and ranges from $64 \%$ (gB), $72 \%$ (MDBP), $73 \%$ (pol), to $74 \%$ (ICP18.5) similarity. The slightly higher similarity to the amino acid sequences of the homologous EBV proteins than 
to the HSV-1 proteins (Elliott et al., 1991; Rapp et al., 1992) suggests a closer relationship of the cytomegaloviruses to the $\gamma$-herpesviruses than to the $\alpha$-herpesviruses.

In conclusion, this report suggests the notion that MCMV and HCMV are not only similar in biology and pathogenesis but also exhibit extensive homology at the nucleic acid level of genes and in the amino acid sequences of proteins. The close relationship of the two cytomegaloviruses underlines the importance of the murine cytomegalovirus as an appropriate model for studying the biology of CMV infections.

\section{ACKNOWLEDGMENTS}

We thank M. Rapp for critical reading of the manuscript and $A$ Luske and B. Reutter for preparation of the photographs. This investigation was supported by SFB 322 Grant C6 from the Deutsche Forschungsgemeinschaft.

\section{REFERENCES}

Addison, C., Rixon, F. J., and Preston, V. G. (1990). Herpes simplex virus type 1 UL28 gene product is important for the formation of mature capsids. J. Gen. Virol. 71, 2377-2384.

ANDERS, D. G. (1990). Nucleotide sequence of a cytomegalovirus single-stranded DNA-binding protein gene: Comparison with at pha- and gammaherpesvirus counterparts reveals conserved segments. J. Gen. Virol. 71, 2451-2456

ANDERS, D. G., and GiBSON, W. (1988). Location, transcript analysis, and partial nucleotide sequence of the cytomegalovirus gene encoding an early DNA-binding protein with similarities to ICP8 of herpes simplex virus type 1. J. Virol. 62, 1364-1372.

ANDERS, D. G., IRMIERE, A., and GIBSON, W. (1986). Identification and characterization of a major early cytomegalovirus DNA-binding protein. J. Virol. 58, 253-262.

ANDERS, D. G., KIDD, J. R., and GIBSON, W. (1987). Immunological characterization of an early cytomegalovirus single-strand DNAbinding protein with similarities to the HSV major DNA-binding protein. Virology $161,579-588$

BiRNSTIEL, M. L., BUSSLINGER, M., and StRUB, K. (1985). Transcription termination and $3^{\prime}$ processing: The end is in site. Cell 41,349 359 .

BÜHLER, B., KEIL, G. M., WEILAND, F., and KOSZINOWSKI, U. H. (1990). Characterization of the murine cytomegalovirus early transcription unit $\mathrm{e} 1$ that is induced by immediate-early proteins. J. Virol. 64, 1907-1919.

Chee, M. S., Bankier, A. T., Beck, S., Bohni, R., Brown, C. M. Cerny, R., Horsnell, T., Hutchison III, C. A., Kouzarides, T., Martignetti, J. A., Preddie, E., Satchwell, S. C., Tomlinson, P., WesTON, K. M., and BARRELL, B. G. (1990). Analysis of the protein-cod ing content of the sequence of human cytomegalovirus strain $A D$ 169. Curr. Top. Microbiol. Immunol. 154, 125-169.

Chirgwin, J. M., Przybala, A. E., Macdonald, R. J., and Rutter, W. J. (1979). Isolation of biologically active ribonucleic acid from sources enriched in ribonuclease. Biochemistry 18, 5294-5299.

DevereuX, J., HaberLI, P., and Smithies, O. (1984). A comprehensive set of sequence analysis programs for the Vax. Nucleic Acids Res. 12, 387-395.

Elliott, R., Clark, C., Jaguish, D., and Spector, D. (1991). Transcription analysis and sequence of the putative murine cytomegalovirus DNA polymerase gene. Virology 185, 169-186.

Frohman, M. A., Dush, M. K., and MARTIN, G. R. (1988). Rapid pro- duction of full-length cDNAs from rare transcripts: Amplification using a single gene-specific oligonucleotide primer. Proc. Natl. Acad. Sci. USA 85, 8998-9002.

GAO, M., BOUCHEY, J., CURTIN, K., and KNIPE, D. M. (1988). Genetic identification of a portion of the herpes simplex virus ICP8 protein required for DNA-binding. Virology 163, 319-329.

GAO, M., and KNIPE, D. M. (1989). Genetic evidence for multiple nuclear functions of the herpes simplex virus ICP8 DNA-binding protein. J. Virol. 63, 5228-5267.

Ho, M. (1982). "Cytomegalovirus: Biology and Infection." Plenum, New York

Holland, L. E., SANDRi-Goldin, R. M., Goldin, A. L., Glorioso, J. C., and LEVINE, M. (1984). Transcriptional and genetic analyses of the herpes simplex virus type 1 genome: Coordinates 0.29 to 0.45 . J. Virol. 49, 947-959

JORDAN, M. C., SHANLEY, J. D., and STEVENS, J. G. (1977). Immunosuppression reactivates and disseminates latent murine cytomegalovirus. J. Gen. Virol. 37, 419-425.

KeIL, G. M., Ebeling-KeIL, A., and KoszinowsKi, U. H. (1984). Temporal regulation of murine cytomegalovirus transcription and mapping of viral RNA synthesized at immediate early times after infection. J. Virol. 50, 784-795.

KeIL, G. M., Ebeling-KeIL, A., and Koszinowski, U. H. (1987). Sequence and structural organization of murine cytomegalovirus immediate-early gene 1. J. Virol. 61, 1901-1908.

Kemble, G. W., McCormick, A. L., Pereira, L., and Mocarski, E. S. (1987). A cytomegalovirus protein with properties of herpes simplex virus ICP8: Partial purification of the polypeptide and map position of the gene. J. Virol. 61, 3143-3151.

Koszinowski, U. H., Del VAL, M., and Reddehase, M. J. (1990). Cellular and molecular basis of the protective immune response to cytomegalovirus infection. Curr. Top. Microbiol. Immunol. 154, 189220.

Kouzarides, T., Bankier, A. T., Satchwell, S. C., Weston, K., TomLINSON, P., and BARRELL, B. G. (1987). Large-scale rearrangement of homologous regions in the genomes of HCMV and EBV. Virology 157, 397-413

LOH, L. C., BaLACHANDRAN, N., and BrIT, W. J. (1991). Characterization of a membrane-associated phosphoprotein of murine cytomegalovirus ( $\mathrm{pp} 50$ ) and its immunological cross-reactivity with a human cytomegalovirus protein. Virology 183, 181-194.

Messerle, M., BüHLER, B., KeIL, G. M., and KoszinowsKI, U. H. (1992). Structural organization, expression, and functional characterization of the murine cytomegalovirus immediate-early gene 3 . J. Virol. 66, 27-36

Pancake, B. A., Aschman, D. P., and Schaffer, P. A. (1983). Genetic and phenotypic analysis of herpes simplex type 1 mutants conditionally resistant to immune cytolysis. J. Virol. 47, 568-585.

PASS, R. F. (1991). In "Progress in Cytomegalovirus Research" (M. P. Landini, Ed.), pp. 3-15. Elsevier Science, Amsterdam.

Pederson, N. E., and Enouist, L. W. (1991). Overexpression in bacteria and identification in infected cells of the pseudorabies virus protein homologous to herpes simplex virus type 1 ICP18.5. J. Virol. 65, 3746-3758.

Pellett, P. E., Jenkins, F. J., Ackermann, M., Sarmiento, M., and ROIZMAN, B. (1986). Transcription initiation sites and nucleotide sequence of a herpes simplex virus 1 gene conserved in the Epstein-Barr virus genome and reported to affect the transport of viral glycoproteins. J. Virol. 60, 1134-1140.

QuinLAN, M. P., CHEN, L. B., and KNIPE, D. M. (1984). The intranuclear location of a herpes simplex virus DNA-binding protein is determined by the status of viral DNA replication. Cell 36, 857868.

RAFIELD, L. F., and KNIPE, D. M. (1984). Characterization of the major mRNAs transcribed from the genes for glycoprotein B and DNA- 
binding protein ICP8 of herpes simplex virus type 1. J. Virol. 49, 960-969.

Rapp, M., Messerle, M., BüHler, B., Tannheimer, M., Kell, G. M., and KoszINOwSKI, U. H. (1992). Identification of the murine cytomegalovirus glycoprotein $B$ gene and its expression in vaccinia virus. J. Virol., 66, 4399-4406.
TABOR, S., and RICHARDSON, C. C. (1987). DNA sequence analysis with a modified bacteriophage T7 DNA polymerase. Proc. Natl. Acad. Sci. USA 84, 4767-4771.

Wu, C. A., Nelson, N. J., McGeoch, D. J., and Challberg, M. D. (1988). Identification of herpes simplex virus type 1 genes required for origin-dependent DNA synthesis. J. Virol. 62, 435-443. 